\title{
A teoria da história de Jörn Rüsen no Brasil e seus principais comentadores
}

The history theory of Jörn Rüsen in Brazil and its main commentators

Wilian Carlos Cipriani Barom*

\section{Resumo}

O presente artigo trata da recepção brasileira da teoria da história de Jörn Rüsen, com especial destaque sobre o campo da Didática da História. A partir de uma revisão da literatura produzida no Brasil, busca identificar as principais contribuições da teoria de Rüsen para a história e seu ensino, de acordo com a opinião de pesquisadores e comentadores nacionais. Utiliza-se de uma amostragem de 34 artigos publicados em revistas e anais eletrônicos de eventos dedicados às áreas de História e Educação. Sintetiza as principais contribuições da teoria em cinco pontos: recuperar o enraizamento da história no cotidiano; compatibilizar método e sentido por meio da narrativa histórica; considerar as informações históricas presentes na sociedade como influência ao pensamento histórico; ser uma porta de entrada para as contribuições alemãs acerca da Didática da História; e possibilitar uma pesquisa no ensino da história que considere as ideias dos estudantes.

Palavras-chave: teoria da história; didática da história; ensino de história.

\section{Abstract}

This article deals with the Brazilian receipt of theory of history Jörn Rüsen, with special emphasis on the field of history didactics. From a review of literature produced in Brazil, aims to identify the main contributions of Rüsen theory for history and its teaching, In accordance with the opinion of researchers and national commentators. It uses a sample of 34 articles published in journals and electronic annals of events dedicated to the areas of History and Education. It summarizes the main contributions of the theory on five points: retrieve the rooting of history in everyday life; reconnect method and sense through historical narrative; consider the historical culture as an influence in historical thinking; be a door of entrance for the German contributions concerning the history didactics; and make possible a research in the history teaching that considers the ideas of the students.

Keywords: history theory; history didactics; history teaching.

\footnotetext{
* Doutorando, Programa de Pós-Graduação em Educação, Universidade Estadual de Ponta Grossa (UEPG). Ponta Grossa, PR, Brasil. wilianbarom@yahoo.com.br
} 
No Brasil, a Didática da História está em movimento. Não sabemos ao certo para onde, mas já podemos perceber algumas marcas deixadas na água. Um barco, ou até mesmo vários barcos, cada um numa direção, em um mar (des)conhecido. Buscam se orientar, na maioria das vezes, com base em instrumentos estrangeiros. O rumo Norte não é garantia de chegada e o porto onde se atracar não está previamente localizado. Ao longo do caminho serão os movimentos de originalidade, a curiosidade atenta e interpretação dos navegadores que vão nos garantir a segurança de trafegar e (re)conhecer as nossas águas.

Instrumentalmente, quando analisamos isoladamente uma dessas embarcações, podemos dividi-la em três partes. Uma divisão não muito rígida.

$\mathrm{Na}$ proa, olhando para frente, alguns pesquisadores vêm discutindo o futuro de nossas pesquisas, uma adequação entre os conceitos, as teorias e a realidade brasileira. Lançam-se no desafio de desbravar o estrangeiro, seja na leitura direta das obras em suas línguas originárias, seja com viagens pessoais, estudos, eventos e orientações internacionais. Com experiências ímpares, promovem traduções desses achados, inserindo novos instrumentos na orientação, tornando acessíveis as discussões e ideias que vêm ocorrendo internacionalmente. Internamente, orientam trabalhos acadêmicos, promovem grupos de pesquisas, eventos nacionais e internacionais, estão em produção constante, atuando no meio acadêmico e fora dele. São intelectuais que arriscam o novo, que apontam para contribuições, que descobrem experiências, teorias e conceitos. Aqui enquadramos as produções de cunho reflexivo, metateóricas, que analisam e problematizam a adequação entre a teoria e a realidade.

No meio da embarcação, que podemos denominar de meia-nau, estão os pesquisadores que recebem essas contribuições, críticas, traduções e novos conceitos e buscam experimentá-los em suas pesquisas empíricas. Normalmente vinculados a programas de pós-graduação ou grupos de estudo e pesquisa, criam perspectivas, formas de utilizar a teoria, testam, corrigem, refutam e fundamentam, produzindo coletivamente e individualmente. Enquadramos aqui as teses, dissertações, monografias, artigos, relatos de experiências, entrevistas, comunicações, obras etc.

O retrato da época, o sentido em que caminha a embarcação, depende da forma como interagem esses navegadores, interna e externamente; de suas relações de grupo, disputas de poder, potencialidade de diálogos, abertura (ou não) a críticas, influências mútuas, estabelecimento de hegemonias, controle 
de espaços políticos etc. Um entendimento da Didática da História no Brasil como um fenômeno plural.

Na popa da embarcação, olhando para trás, localizam-se os pesquisadores que buscam analisar o que foi efetivamente feito pela meia-nau. Eles atentam ao fato de haver dois degraus a serem considerados: um entre o conteúdo da teoria e o entendimento do pesquisador e outro entre esse entendimento e a utilização prática em sua pesquisa. Assim, esses pesquisadores da popa buscam construir uma provisória ideia do todo, por meio da comparação, analisando as produções internamente e também externamente, numa espécie de sociologia crítica da produção científica. São intelectuais que observam os desenhos deixados nas águas, buscam dar formas e entendimento a esses desenhos e identificar, em meio às curvas, o sentido em que anda a embarcação.

Essa arquitetura provisória tem aqui função instrumental e analítica. Em função da pluralidade das perspectivas e teorias que atualmente fundamentam as pesquisas sobre o ensino da história no Brasil, que em muito se desenvolvem em diálogo com as transformações internas à área da ciência da História, torna-se necessário fazer um recorte. Assim, escolhemos considerar a influência particular da teoria da história do filósofo alemão Jörn Rüsen nas produções acadêmicas e sintetizar aqui as principais contribuições dos intelectuais que estão na proa, discutindo essa teoria e a sua aplicação. Mais especificamente, como esses intelectuais justificam a utilização dessa teoria em seus textos e que importância atribuem a ela.

Quando observamos o todo, ou ao menos algo próximo ao todo das produções que se utilizam da teoria rüseniana no Brasil, podemos afirmar que o cenário nacional vem crescendo exponencialmente.

No ano de 2012, quando levantados os trabalhos acadêmicos sob essa influência ${ }^{1}$ a partir de um recorte de 2001 a 2010, encontrou-se a totalidade de 75 artigos, 37 dissertações, 14 teses e 1 monografia (Barom, 2012; 2014). Quando atentamos isoladamente para as teses, dissertações e monografias, registrou-se uma amostragem de $64,1 \%$ de produções realizadas nos programas graduação e pós-graduação em História, e 34\% nos programas de pós- graduação em Educação. Houve também uma dissertação realizada no programa de pós-graduação em Relações Internacionais da Universidade de Brasília (UnB). Uma vez que esses dados já foram analisados e publicados, não pretendemos repetir ou aprofundar tal análise neste espaço. Apenas 
gostaríamos de deixar indicado o significativo aumento nas produções a partir de uma atualização dos dados realizada recentemente (setembro/2015) com as mesmas ferramentas, a Plataforma Lattes e o sítio Google Acadêmico. ${ }^{2}$ Estendendo o recorte a 2015, temos os seguintes dados: 562 artigos, 75 dissertações, 28 teses e 2 monografias. Da mesma forma, atentando isoladamente às dissertações, teses e monografias podemos registrar 72,6\% nos programas de graduação e pós-graduação em Educação (21 teses, 55 dissertações e 1 monografia), 26,4\% de produções realizadas nos programas de graduação e pós-graduação em História (7 teses, 20 dissertações e 1 monografia), mais o trabalho produzido pela área de Relações Internacionais. Quando dividimos, instrumentalmente, todas as publicações em antes e depois de 2010, podemos assinalar um crescimento de $66 \%$ nas produções acadêmicas, atentando ao significativo crescimento dos trabalhos realizados pelos programas de graduação e pós-graduação em educação.

Dividindo essas publicações de teses, dissertações e monografias por universidade, o que nos apontaria geograficamente o impacto da teoria rüseniana, temos: UFPR (37), USP (15), UEPG (14), UNB (11), Unicamp (7), UEL (), UFPB (04), UFG (03), Ufop (3), UFSC (3), UFMG (1), UFRGS (1), UFRJ (1), UFS (1), Unesp (1). Nesses trabalhos, destacamos os significativos esforços de orientação dos professores e professoras Ernesta Zamboni, Estevão Chaves de Rezende Martins, Luis Fernando Cerri, Luiz Sérgio Duarte da Silva, Kátia Maria Abud, Tânia Maria Figueiredo Braga Garcia, Marlene Rosa Cainelli e Maria Auxiliadora Moreira dos Santos Schmidt. ${ }^{3}$

Retornando a nossa questão principal, como os pesquisadores nacionais justificam a utilização da teoria rüseniana e que importância atribuem a ela, escolhemos aqui observar apenas as produções acadêmicas em formato artigo, publicados em revistas ou anais de eventos. Curiosamente, a partir de nosso último levantamento, percebemos que as contribuições disponibilizadas em formato artigo vêm tendo maior influência do que as teses, dissertações e monografias. Ao observarmos as referências bibliográficas dos trabalhos, percebemos suposto desconhecimento recíproco entre as pesquisas de temas próximos, o que acontece em menor intensidade quando se trata dos artigos. Uma "cartografia do conhecimento científico" (Barom, 2012, p.71), expressão desenvolvida na intenção de dar conta dessa prática centrípeta de citações ao redor de um suposto núcleo. Via de regra, o orientador e os trabalhos de sua 
esfera de orientação acabam por limitar o conhecimento recíproco entre as pesquisas nacionais. Tal fenômeno, aparentemente, ocorre em menor intensidade quando essas informações estão dispostas no formato artigo. Ainda assim, esse núcleo de poder/influência pode ser visualizado. ${ }^{4}$

Desse modo, quando observamos os resumos, títulos e palavras-chave dos artigos de nosso levantamento, identificamos um total de 34 artigos que se relacionam, direta ou indiretamente, à questão que propusemos. Esses pesquisadores, por apresentarem experiências anteriores e recentes com orientações de trabalhos acadêmicos, histórias de vidas relacionadas com o estudo da História e do ensino da História, acabam por projetar análises, expectativas de futuro nesse campo, estabelecendo comparações com as referências anteriores à influência rüseniana. Estamos nos referindo a artigos nacionais publicados pelos seguintes pesquisadores: Arthur Alfaix Assis, Estevão Chaves de Rezende Martins, Itamar Freitas de Oliveira, Luis Fernando Cerri, Margarida Maria Dias de Oliveira, Maria Auxiliadora Moreira dos Santos Schmidt, Oldimar Pontes Cardoso, Pedro Caldas, Rafael Saddi, Raphael Guilherme de Carvalho, Rogério Chaves da Silva, Ronaldo Cardoso Alves, Wilian Carlos Cipriani Barom e Wilson de Sousa Gomes.

Assim, podemos distribuir em cinco pontos as contribuições da teoria da história de Jörn Rüsen para as pesquisas que versam sobre a História e o seu ensino: recuperar o enraizamento da história no cotidiano; compatibilizar método e sentido, por meio da narrativa histórica; considerar as informações históricas presentes na sociedade como influência ao pensamento histórico; ser uma porta de entrada para as contribuições alemãs acerca da Didática da História; e possibilitar uma pesquisa no ensino da história que considere as ideias dos estudantes.

\section{“ENRAIZAMENTO DA HISTÓRIA NO COTIDIANO DA VIDA PRÁTICA"5}

Nos textos analisados é bastante comum atribuir a Rüsen o destaque em recuperar a ligação existente entre a história produzida pelo historiador e as carências de orientação de seu tempo. O lugar da história na sociedade, sua íntima relação com o cotidiano da vida prática (práxis da vida) e o papel que desempenha como orientação ao retornar como produto historiográfico são algumas das questões registradas. 
Para o professor Pedro Caldas (2008, p.8), Rüsen traz para o debate, de modo bastante direto, o aspecto pedagógico da ciência da História, muito renegado ao longo do século XX. Por isso, na visão do autor, é um ganho para o debate recuperar o historicismo ${ }^{6}$ de Droysen, na intenção de reinserir na reflexão historiográfica a preocupação didática com a orientação do conhecimento científico. O historiador deve ter a "coragem" de se perguntar sobre a necessidade daquilo que faz, deve contribuir para o alargamento dos horizontes intelectuais e práticos da vida humana, deve atentar constantemente para a lembrança de sua especificidade, qual seja, "perceber que tipo de perguntas (e respostas) somente a historiografia pode trazer", que colaborem na orientação do presente (Caldas, 2008, p.8). Nas palavras de Wilson de Souza Gomes, a história como "ação reflexiva para sentido do sujeito histórico" (Gomes, 2012, p.180).

Esse posicionamento de Rüsen, de refletir intencionalmente sobre os fatores e fundamentos da Ciência Histórica, possibilita, no âmbito da Teoria da História, a superação da redução dos estudos à metodologia da pesquisa. Para Rafael Saddi, com a matriz disciplinar sistematizada por Rüsen, em especial a sua atenção dada às categorias de interesses e funções, é que se evidencia a linha tênue entre o pensamento histórico regulado cientificamente e a vida prática (Saddi, 2010, p.71). Um reconhecimento de que essas duas categorias estão intimamente presentes no trabalho do historiador, mesmo que se tenha insistido, ao longo da história da historiografia, em negar essas dimensões em favor de uma suposta objetividade científica. O labor historiográfico deve ser norteado "exatamente por essa relação intrínseca entre História e Vida", sem a qual não haveria sentido em construir racionalmente o conhecimento histórico (Alves, 2013, p.54). "Para que serve a História?", na pergunta provocativa exposta por Ronaldo Cardoso Alves, que, em consonância com a discussão anterior, aponta para a necessidade de transformar a "'realidade instrumental ideológica da História’ em um instrumento de autorreflexão pública que permita às pessoas e aos grupos construir identidade e se colocar autonomamente diante dos problemas de orientação temporal (im)postos pelo cotidiano" (Alves, 2013, p.57).

Ou seja, Rüsen propicia uma reflexão teórica detalhada de como o ganho qualitativo, oriundo da regulação metódica científica, retorna como possibilidade de orientação individual e de grupo, para problemas cotidianos de 
orientação temporal. Saddi, em outro texto mais recente (Saddi, 2014, p.138), corrobora essa ideia ao localizar no contexto alemão os esforços de Rüsen em entender a teoria da história como Historik, isto é, como meta-história, como uma reflexão teórica sobre a práxis historiográfica, em que identifica os "fundamentos mundanos de toda e qualquer história”. Observando metateoricamente o trabalho historiográfico, Rüsen elaborou sua teoria de modo a relacionar internamente carências, ideias, método, forma e função. Das angústias de orientação (individuais e coletivas de uma época) à metodologia científica da história, para então se apresentar singularmente em sua forma escrita, retornando à sociedade com a função de orientação. O produto historiográfico surge como uma resposta, com certo ganho qualitativo de orientação, à angústia inicial.

\section{“CompatibilizAÇÃo ENTRE MÉtodo E SENTIDO, ENTRE PRETENSÃo DE VALIDADE CIENTÍFICA E INTENÇÃo DE PRODUZIR EFEITO” †}

Ao propor dialogar com a historiografia contemporânea, especialmente com Hayden White, Rüsen considera pertinentes as preocupações do autor sobre a narrativa histórica, ao mesmo tempo em que busca recuperar a centralidade do método histórico na ciência da história (Gomes, 2012). Aos moldes das grandes teorias da história do século XIX, a teoria da história de Jörn Rüsen busca refutar a ideia reducionista da História como ficção, ou literatura, redirecionando o papel da linguagem na prática cotidiana do historiador. ${ }^{8}$ Este seria o ganho em sua teoria: a articulação da racionalidade metódica com o sentido, por meio da narrativa histórica (Assis, 2010a).

Rüsen demonstra como o sentido, derivado da carência de orientação, participa da regulação metódica e retorna como orientação, que só é possível por intermédio da linguagem, da narrativa histórica. Se, por um lado, os historiadores da "virada linguística" acertaram em destacar e desenvolver a importância da retórica e da estética como colaboradoras na atribuição de sentido, ${ }^{9}$ por outro lado, essas dimensões só não estariam, segundo Rüsen, desconectadas do ganho de racionalidade oriundo da regulação metódica e do sentido inicial proveniente das carências de orientação.

Assim, Rüsen atribui a devida importância ao caráter narrativo, o que poderia situar, em certa medida, sua obra no chamado narrativismo, ressalvada 
a relação que estabelece entre narrativas históricas e a "realidade histórica". A narrativa histórica revela uma forma de realismo distinta do realismo literário, ou seja, "o fato de as narrativas históricas rememorarem a experiência do passado por meio de representações da continuidade temporal - as quais ao mesmo tempo sustêm a formação de identidades no presente - confere à historiografia uma característica específica” (Assis, 2010a, p.13).

Nesse sentido, Rüsen diferencia a narrativa comum da narrativa histórica, considerando a particularidade desta última ao rememorar dados do passado, articular passado-presente-futuro e colaborar na identidade do sujeito no presente. O texto historiográfico, então, colaboraria como orientação ao presente, mas não deve ser entendido isoladamente das outras dimensões da matriz disciplinar de Rüsen, que teriam igual valor/importância nesse processo final de orientação para a vida prática.

Assim, Rogério Chaves da Silva aponta como uma das contribuições rüsenianas, em meio à intenção de compatibilizar pretensão de validade e intenção de produzir efeito, a importância da mediação narrativa como parte constituinte do conhecimento histórico, "pois a conexão entre a experiência humana do passado, extraída a partir da pesquisa, e as demandas por sentido requeridas pela vida humana do presente, somente se dá através da historiografia (produto intelectual narrativo construído por historiadores)" (Chaves da Silva, 2009, p.174).

Assumir essa ligação entre método e sentido, por meio da narrativa histórica, não significa atenuar os índices de cientificidade do pensamento histórico, mas antes convencer-se de que a subjetividade não precisa ser reprimida, e sim "ordenada e admitida de forma adequada e compatível com a cientificidade do conhecimento científico" (Chaves da Silva, 2009, p.176).

Ao propor que a regulação metódica não inviabiliza o trabalho de produção de sentido de que está revestido o conhecimento histórico, Rüsen estaria sugerindo uma mediação entre o extremismo da objetividade estreita - em que os métodos seriam meios infalíveis para descortinar verdades escondidas nas fontes, o que excluiria uma ideia de representação na história - e o radicalismo do construtivismo narrativista, que declinaria em direção à ficcionalidade, à história como literatura.

Sobre esse assunto, nas palavras de Raphael Guilherme de Carvalho, 
Como uma referência imprescindível da formação do pensamento histórico moderno, Rüsen renova essa tradição [projeto kantiano de esclarecimento], incorporando e respondendo às críticas dos pós-estruturalistas e pós-modernos, de modo que não basta mais apenas a conservação da racionalidade dos métodos de pesquisa (heurística, crítica e hermenêutica) sem avançar na direção das técnicas narrativas (retóricas e estéticas) na historiografia. Mas somente o procedimento metódico é capaz de preservar o risco do devaneio ficcional. (Carvalho, 2011, p.19)

Assim, podemos concluir, na expressão sintética de Ronaldo de Cardoso Alves, "dotar de sentido a racionalidade histórica" (2013, p.58) é o desafio a que se lança Rüsen de modo a articular história e vida prática (práxis da vida), relacionando os métodos de pesquisa (heurística, crítica e hermenêutica) e as técnicas narrativas (retórica e estética), numa possível mediação entre objetividade e subjetividade.

\section{“Após DOIS SÉCULOS DE 'COMBATES PELA HistóRIA', O CONHECIMENTO HISTÓRICO ACADÊMICO LOGROU TORNAR-SE A PRINCIPAL REFERÊNCIA PARA O PENSAR HISTORICAMENTE DA SOCIEDADE, MAS O MOMENTO EXIGE QUE SE RECONHEÇA QUE NÃO É O ÚNICO” ${ }^{10}$ - CONSIDERAÇÕES SOBRE A CULTURA HISTÓRICA}

Na teoria rüseniana, ao se desconstruir a ideia do método como algo estritamente objetivo, vincula-se a ciência da história (e o historiador) a uma cultura histórica. Em outras palavras, submete-se a racionalidade ao tempo (Razão Histórica). Essa preocupação em entender os movimentos da história, localizando os indivíduos no tempo, mediando estrutura e intencionalidade, acaba por abrir um espaço na teoria de Rüsen, em torno do conceito de cultura histórica, que vem se mostrando extremamente promissor ao ensino da história.

Em sua teoria, para melhor desenvolver a sua apropriação do conceito de consciência histórica, Rüsen busca demonstrar como os fundamentos do pensamento histórico estão presentes no cotidiano do historiador. ${ }^{11}$ A partir de seus apontamentos sobre a interpretação como condição humana ao agir, e que para interpretar o sujeito mobiliza um quadro informativo mínimo oriundo da memória, que se relaciona com as experiências cotidianas, Rüsen aponta a 
consciência histórica como um "fenômeno do mundo vital" (Rüsen, 2001, p.56), uma forma de consciência humana comum a todas as pessoas. Inclusive ao historiador, que ao mobilizar suas fontes, utilizar-se de seu método, também carrega em si um conjunto de informações do passado oriundas do cotidiano.

Assim, teríamos na memória ideias e informações originadas das experiências cotidianas e, também, dos produtos historiográficos, conhecimentos regulados metodicamente, que estão dispostos no cotidiano. Daí derivam os conceitos rüsenianos de formação complementar e formação compensatória, de modo a operacionalizar a ação da cultura histórica sobre o sujeito. ${ }^{12}$ Uma cultura que colabora na formação das ideias históricas das pessoas. Um sentido dado pela cultura, o agir passado como direção imediatamente eficaz ao presente (Rüsen, 2001, p.77), que é interpretado pelo sujeito, conforme as suas carências e interesses.

Desse modo, discutir a dialética entre sujeito e estrutura em Rüsen passa necessariamente pela articulação dos conceitos cultura histórica, formação histórica, tradição, crise e consciência histórica. ${ }^{13}$

Podemos apontar um (aparente) paradoxo da questão da seguinte maneira: é pela consciência histórica que se supera, ou até mesmo se reproduz, uma dada cultura histórica. Acreditamos aqui que a consciência histórica pode estar ou não atrelada a uma dada cultura histórica, em maior ou menor grau.

Não pretendemos entrar na discussão acerca do limite da inter-relação entre a consciência de um indivíduo e a consciência da coletividade à qual pertence o indivíduo. Por ora, apenas indicamos a possibilidade da existência de certa autonomia da consciência histórica com relação à cultura histórica dominante. $\mathrm{Ou}$, até mesmo, podemos pensar em nichos de consciência histórica, consciências históricas desviantes, ou uma cultura histórica que não seja unívoca ou homogênea, ou ainda, mesmo hegemônica, sujeita a contra-hegemonias.

Mas, o que queremos apontar neste momento é a consideração da cultura histórica, das informações históricas presentes na sociedade como realidade com a qual as pessoas se relacionam obrigatoriamente, no processo de formação de seus quadros próprios de entendimento. Desse modo, como forma de orientação, o conhecimento histórico científico estaria disposto na sociedade, assim como estariam também os conhecimentos históricos não regulados metodicamente. De acordo com Estevão de Rezende Martins, a contribuição de 
Rüsen seria articular, de modo integrado, as cinco fases da historização do tempo e do espaço humano: a experiência, a reflexão sobre a experiência, o pensamento histórico, a consciência histórica e a cultura histórica (Martins, 2012, p.68). Essa articulação desmonta a divisão polarizada entre ciência e senso comum, ao inserir a subjetividade no processo de reflexão sobre a experiência, a partir do pensamento, em meio a uma relação dialética com a cultura. ${ }^{14}$ Portanto, Rüsen traz para o centro da discussão não somente a defesa do método frente aos ataques da pós-modernidade, mas também um estudo teórico detalhado sobre a formação do pensamento histórico comum no interior da sociedade, no interior da cultura. Parafraseando Rüsen, o cotidiano do historiador, seu tempo, sua cultura, passam a constituir a base natural da teoria da história (Rüsen, 2001, p.25).

\section{“O MODO COMO A DIDÁTICA DA HISTÓRIA ALEMÃ TEM SIDO APROPRIADA NO BRASIL" - AMPLIAÇÃO DO CONCEITO DE DidÁticA DA História}

Podemos propor que as traduções de Rüsen no Brasil, com especial destaque às obras Razão Histórica (2001), Reconstrução do Passado (2007a) e História Viva (2007b), traduzidas por Estevão de Rezende Martins e Asta-Rose Alcaide, foram a porta de entrada para as discussões alemãs acerca da ampliação do conceito de Didática da História, que ocorreram no final da década de 1960. Por isso, muitas vezes, as confusões em atribuir a Rüsen a ampliação desse conceito, mesmo com a publicação anterior no país de A História na reflexão didática, de Klaus Bergmann, em 1990. Quem vem relocando e corrigindo essas informações é Rafael Saddi, em seus textos mais recentes (Saddi, 2012; 2014), ao se esforçar em inserir o pensamento de Rüsen num contexto geracional, em inter-relação com Schörken, Bergmann, Pandel e Jeismann. Mas, independentemente da originalidade ou autoria da ideia, o fato é que no Brasil, conforme os pesquisadores e grupos foram aprofundando seus conhecimentos no pensamento rüseniano, maior foi o apego à ideia de uma Didática da História ampliada, já que essa ideia está posta e sistematizada nos escritos de Rüsen.

A consideração da formação do pensamento histórico comum, da cultura histórica, da inserção do historiador no tempo e no espaço histórico, da ciência 
como orientação para a vida, disposta igualmente na sociedade, amplia as fronteiras da disciplina Didática da História, de modo a melhor se compreender o fenômeno do pensamento histórico.

No Brasil, Luis Fernando Cerri, Oldimar Cardoso e Rafael Saddi vêm costurando uma discussão, refletindo em que medida as contribuições alemãs podem ser mais bem aproveitadas. Atualmente, a tônica da discussão parece recair sobre o local da disciplina Didática da História no interior do contexto institucional universitário. O que parece ser uma mera questão prática e política, na verdade remete a uma discussão profunda sobre o local da disciplina entre as áreas da ciência da História ou ciência da Educação, ou até mesmo num espaço de fronteira, inter-relação e interdisciplinaridade.

De modo sintético, assumir a Didática da História como subdisciplina da Ciência da História, cujo objeto seria o aprendizado histórico, significaria, na prática, deslocar "a Didática da História do campo das teorias sobre a metodologia do ensino, da centralidade do ato de ensinar, para o campo das reflexões sobre o aprendizado histórico, que delimita a ação dos educadores e os obriga a entender a educação histórica como um conjunto de fatores, não só como o resultado do ensino" (Cerri, 2005, p.14).

Apoiando-se em Rüsen e Bergmann, Cerri aponta para a necessidade de adentrar o "campo inexplorado" do significado da História no contexto social, mais precisamente, "entender os múltiplos focos de emancipação dos discursos históricos" na sociedade, e como "atribuem sentido aos grupos humanos no tempo" (Cerri, 2005, p.13). Assim, a Didática da História, ao distanciar-se da Didática Geral, ganharia amplitude ao entender o aprendizado histórico como fenômeno social, inclusive na observância atenta da dimensão didática do discurso historiográfico, e como ele interfere na sociedade. Seria uma ampliação da área, no estudo dos encontros e desencontros do conhecimento histórico comum com o conhecimento histórico científico, no interior da sociedade. Um alargamento da ideia de Didática da História para além do “campo restrito da metodologia de ensino" (Cerri, 2010, p.268).

Essa guinada, com base na forte influência de Rüsen nas pesquisas educacionais que versam sobre o ensino da História, é o que Cerri vem denominando de "processo de mudança paradigmática da didática da história no Brasil" (Cerri, 2010, p.277). Esse processo pode ser mais bem entendido a partir das quatro ampliações da Didática da História sintetizadas por Saddi (2012): o 
questionamento da redução dessa disciplina à metodologia de ensino; o questionamento da redução da didática da história à escola; o questionamento da separação entre didática da história e ciência histórica; e o processo interno de definição dos próprios conceitos e campo de investigação. Para o autor, essas ampliações estariam ocorrendo no cenário nacional a partir do desenvolvimento crescente das pesquisas empíricas, com especial destaque para o encontro da metodologia inglesa History Education com as ideias sistematizadas de Rüsen, mediante os esforços nacionais de Maria Auxiliadora Moreira dos Santos Schmidt e do grupo da Educação Histórica (Saddi, 2014, p.135). ${ }^{15}$

\section{“A AQUISIÇÃO INCONDICIONAL DA COMPETÊNCIA NARRATIVA POR PARTE DE ALUNOS E PROFESSORES, NA PERSPECTIVA DA MULTIPERSPECTIVIDADE E PLURALIDADE" ${ }^{16}$ - O ENSINO E A COMPREENSÃO DAS IDEIAS HISTÓRICAS}

Quando questionada sobre qual a principal contribuição da teoria rüseniana no Brasil, após sua fala na mesa intitulada "Contribuições do pensamento de Jörn Rüsen para pesquisas em Educação Histórica”, a professora Marlene Cainelli afirma: "a consideração das ideias dos alunos no processo de ensino e aprendizado". ${ }^{17}$ Visando pensar o ensino da História a partir das elaborações próprias do pensamento histórico, utilizando-se de certo acúmulo teórico e epistemológico da Ciência da História, o grupo curitibano da Educação Histórica vem produzindo, substancialmente, pesquisas na área do ensino da história considerando as ideias dos estudantes e professores. Seja pela constatação ou evolução dessas ideias, as pesquisas buscam interferir qualitativamente no ensino prático da história, de modo a desenvolver as competências narrativas dos jovens estudantes. Nesse sentido, "este processo envolve o desenvolvimento de competências cognitivas históricas específicas, como a identificação e o trabalho com as fontes e, a partir delas, a construção de explicações históricas argumentadas e sua expressão por meio de narrativas, sejam elas 'breves' ou não” (Schmidt, 2014, p.46).

Colaboram, portanto, na ampliação prática do conceito de Didática da História, ao deslocarem (relativamente) o processo do aprendizado histórico das teorias educacionais e psicológicas, referência padrão no entendimento do processo no país, para as contribuições internas à epistemologia da ciência da 
História, acerca do pensamento histórico e seus processos cognitivos. Assim, as discussões anteriores sobre o pensamento histórico, cultura histórica, ciência e vida prática, discussões sistematizadas por Rüsen no que se refere à ciência da história e que aludem a todos os seres humanos, ganham direta significância para as pesquisas que versam sobre o ensino da História.

Nesse sentido, ao possibilitar a consideração das ideias dos estudantes, a teoria rüseniana vem ao encontro da cultura educacional freireana no país, que buscava um projeto de ensino capaz de superar o modelo de ensino como transmissão, "rumo a ideia de um saber que só concretiza a sua necessidade se é aplicável e faz diferença na capacidade do sujeito de agir no mundo em sintonia com sua progressiva leitura desse mesmo mundo" (Cerri, 2010, p.270). Isso significa partir da dialogicidade para se gerar a capacidade de se orientar no tempo de acordo com a própria identidade, considerando o conjunto de elementos históricos intervenientes na vida prática e o conjunto de ideias e argumentos presentes no mundo cultural.

Esse ensino não se resume à ideia de transmissão, ou até mesmo de transposição, mas deriva do desenvolvimento da competência narrativa. É pelo texto escrito, ou pela organização das palavras no ato da fala, quiçá pela linguagem artística, que mobilizamos o passado para interpretar o presente e projetar futuros possíveis. Dentre as operações mentais a serem desenvolvidas, atenta-se para a ampliação das experiências, interpretação e orientação dos jovens, do ponto de vista da multiperspectividade e pluralidade, considerando a possibilidade de tipos variados de sentidos nas narrativas. Assim, o aprendizado pode ser considerado histórico quando,

como atividade da consciência histórica, produz uma ampliação da experiência do passado humano, um aumento da competência para a interpretação histórica dessa experiência e reforço da capacidade de inserir e utilizar interpretações históricas no quadro de orientação da vida prática. Em nada valeria um amplo saber histórico, sabido de cor, que não orientasse para a vida prática. (Barom; Cerri, 2011, p.6)

Não se trata mais de transferir conteúdos, como diriam os slogans "formar alunos críticos”, “torná-los conscientes”, "ser cidadão”, mas parece que a pesquisa sobre o ensino da história no Brasil, com base em nossa amostragem, vem compreendendo que a criticidade e a consciência não são posicionamentos 
diretamente resultantes dos conteúdos curriculares, mas modos de operação da consciência histórica. Assim, as pesquisas não buscam ensinar a "ser crítico", ou a "ter consciência", mas buscam analisar e entender como os jovens operam a utilização do passado (conhecimento comum e científico) na orientação prática de suas vidas. Essa operação só pode ser evidenciada por sua exteriorização mediante linguagem, na qual, contida e mergulhada em subjetividades e interpretações, é possível demonstrar o pensamento e o entendimento do mundo. Nas palavras de Schmidt,

Um primeiro pressuposto é o de que o professor (historiador) não pode, em hipótese alguma, ser um mero reprodutor/transmissor, depositador de conhecimentos nos alunos... finalidade do ensino de História é a formação da consciência histórica do sujeito criança e sujeito jovem e de que esse sujeito está em relação dinâmica com a cultura histórica da sociedade em que vive. (Schmidt, 2014, p.43)

Parece razoável, então, substituirmos a ideia da transmissão do conhecimento científico no ambiente escolar, pela ideia da "internalização como subjetivação" (Schmidt, 2015, p.96), a qual se refere ao processo de interiorização levando em conta as ações dos sujeitos, com vistas às intervenções e transformações na vida humana prática.

Portanto, estaríamos guinando na direção da observação de como os jovens se apropriam cognitivamente da intervenção pedagógica e de em que medida essa apropriação se reflete em suas ações. Isso não distancia a utilização de Rüsen no Brasil das outras abordagens que se julgam críticas, progressistas, ou militantes, uma vez que a consideração das ideias dos jovens não está sendo realizada em detrimento do conhecimento científico, e sim o contrário.

\section{CONSIDERAÇÕES FINAIS}

De modo breve, de acordo com os comentadores analisados, identificamos cinco contribuições da teoria rüseniana para as pesquisas que versam sobre a História e o ensino da História: consideração do enraizamento da história na vida prática; a articulação da racionalidade metódica com o sentido, mediante narrativa histórica; consideração do pensamento histórico no 
interior da cultura histórica; ampliação do conceito de Didática da História; e a consideração das ideias históricas pelas pesquisas educacionais e ensino escolar. Não estamos em condição de detalhar a originalidade de Rüsen no interior dessas cinco contribuições apontadas. É bastante provável que outras teorias, de certa forma, também viessem costurando tais colaborações na cultura da pesquisa histórica, ou educacional, em nível nacional. Contudo, esses apontamentos foram encontrados nas publicações dos pesquisadores que atualmente trabalham com a teoria rüseniana e que, volta e meia, justificaram a presença dessa teoria com base nesses pontos.

Recuperando nossa metáfora da embarcação, quando retornamos à área da meia-nau, ao efetivamente feito, podemos perceber que as pesquisas educacionais sobre o ensino da História estão pactuando esses cinco pontos.

Do enraizamento da história na vida prática tem-se uma resposta provisória às carências que atualmente rondam o ensino escolar da História, qual seja, a derrubada do "modelo hegemônico de ensino de História", ${ }^{18}$ único e padrão, que atribuía sentido e significado ao ensino da História no período da Ditadura Militar Brasileira, que atualmente não existe mais. Angústia criativa representada na ideia de "crise" de orientação, apontada por Elza Nadai (1993, p.144) ao referir-se ao início da década de 1990 e às múltiplas possibilidades, teorias e conceitos que passaram a disputar espaço no interior do ensino da História, reflexo dos acontecimentos internacionais na área dessa ciência. Podemos, então, apontar que relacionar história e vida no interior das discussões científicas gera, como consequência, um novo sentido e significância ao ensino escolar da História. Um caminho de resposta à velha pergunta dos estudantes: "professor, pra que serve isso?".

Da consideração da narrativa pela Teoria da História de Jörn Rüsen, que atentou à universalidade de sua dimensão humana, tem-se a intenção das pesquisas educacionais em estender esse conceito às práticas escolares: as narrativas de estudantes, dos professores, dos meios midiáticos, dos livros didáticos, dos políticos, dos religiosos, das normativas educacionais etc.

Da constatação do pensamento histórico no interior da cultura tem-se um ganho qualitativo no que antes era entendido como as "ideias iniciais dos alunos". É uma compreensão mais dialética dessas ideias, ao considerar que não se trata mais de substituí-las, em definitivo, por ideias científicas. As próprias "ideias iniciais" carregariam em si a mescla entre ciência e não ciência, e a 
intervenção pedagógica não seria, simplesmente, assimilada passivamente pelos estudantes, mas antes interpretada por seus quadros próprios de entendimento. O conhecimento escolar é, então, compreendido em relação com os outros tipos de conhecimentos dispostos no interior da sociedade.

E, da ampliação do conceito de Didática da História e da consideração das ideias históricas, o que podemos perceber é um movimento gradual das pesquisas educacionais "para além da sala de aula", no estudo teórico e empírico da sociedade como um todo (Barom, 2012, p.89).

Concluindo, entendemos que, direta ou indiretamente, versamos aqui sobre as possíveis carências na pesquisa educacional na área do ensino da História a partir da opinião de alguns dos comentadores e pesquisadores de Jörn Rüsen no Brasil. São preocupações, de certo modo, metateóricas caracterizadas na ideia de proa, enunciada no início de nosso texto. Em complemento, quando observamos os trabalhos empíricos realizados pelos pesquisadores vinculados aos programas de pós-graduação em Educação (21 teses, 55 dissertações e 1 monografia), indicados anteriormente, podemos também perceber possíveis carências e interesses que adentram ou refletem o entendimento do ambiente escolar com base no isolamento das temáticas dessas pesquisas. São elas: Ditadura Militar Brasileira; Ditadura Militar Uruguaia (pesquisa realizada com estudantes uruguaios); a banalização da morte; a identidade alemã nos dias de hoje; o papel da mulher na sociedade brasileira; a representação que temos dos Estados Unidos; o Islamismo; a Guerra do Paraguai; o desvelamento da democracia racial brasileira; os documentos sobre a escravidão no Brasil; exercício e participação política dos estudantes; a ideia de cidadania; o passado do Paraná; o futuro individual e da coletividade na opinião dos jovens; a identidade Sem Terra nos dias de hoje; as imagens televisivas; a música popular, de protesto e caipira; fotografias e a classe trabalhadora, a linguagem virtual da internet; a identidade na Cibercultura; a relação histórica e cultural entre Brasil e Portugal, e cultura e história do continente africano. Ao redor desses temas, a pesquisa acadêmica vem adentrando o ambiente escolar com seus estudos, diagnósticos, intervenções, práticas de aula e perspectivas de ensino. No âmbito restrito das pesquisas acadêmicas em educação, podemos entender que a Didática da História vem se construindo, unindo história e vida prática (práxis da vida), na busca pelo desenvolvimento dessas temáticas, considerando as narrativas dos sujeitos, os dados da cultura, o pensamento histórico comum 
em diálogo com o pensamento histórico científico, articulando memória do passado, interpretação do presente e perspectivas de futuro.

Ainda, consideramos sábio o apontamento, em tom irônico, de Itamar Freitas de Oliveira e Margarida Maria Dias de Oliveira, que tiveram a iniciativa de escrever um texto alertando para a suposta apropriação exagerada de Rüsen pelas pesquisas educacionais, qualificando-o como um teórico eclético, um suposto "mais do mesmo", e que sua apropriação estaria resultando numa redução, no currículo escolar, do conhecimento histórico científico, resumindo o ensino àquilo que o aluno quer aprender, de modo prazeroso, em tom pragmático (Freitas; Oliveira, 2014). Discordamos do tom generalizante desse posicionamento, mas acreditamos que essa crítica é infinitamente enriquecedora para o debate.

$\mathrm{Na}$ esteira das traduções recentes da teoria de Jörn Rüsen no Brasil, no ano de 2015 os grupos de pesquisa começaram a apontar rumo ao estudo da interculturalidade, do humanismo, da dignidade humana e identidade em contexto de globalização, a partir da inserção das categorias "inumanidade", "sofrimento" e "História como conflito" ${ }^{19}$ Um novo desafio posto ao ensino da História e à pesquisa educacional. Novos instrumentos estão sendo acrescentados. Seriam estes os novos horizontes?

Segue a embarcação...

\section{REFERÊNCIAS}

ALVES, Ronaldo C. Da Consciência Histórica (Pré) (Pós?) Moderna: reflexões a partir do pensamento de Reinhart Koselleck. Saeculum, João Pessoa: UFPB, v.30, p.321339, 2014a.

. Das causas e consequências na aprendizagem histórica: um estudo a respeito da significância histórica. Revista Eletrônica Documento/Monumento, v.12, p.165-191, 2014b. Disponível em: http://200.129.241.80/ndihr/revista/revistas-anteriores/revista-dm-12.pdf .

. História e Vida: o encontro epistemológico entre Didática da História e Educação Histórica. História \& Ensino, v.19, p.49-69, 2013. Disponível em: http:// www.uel.br/revistas/uel/index.php/histensino/article/view/15535.

. Por um Ensino de História com Sentido para a Vida. Diálogos, Maringá, PR, v.19, p.323-343, 2015.

ASSIS, Arthur Alfaix. A ciência da história como resposta racional a carências de 
orientação. (Resenha de Razão Histórica, de Jörn Rüsen). História Revista, Goiânia: UFG, v.9, n.2, p.331, 2004.

ASSIS, Arthur Alfaix. A teoria da história de Jörn Rüsen. Uma introdução. Goiânia: Ed. UFG, 2010a.

. A teoria da história como hermenêutica da historiografia: uma interpretação de Do Império à República, de Sérgio Buarque de Holanda. Revista Brasileira de História, v.30, p.91-120, $2010 \mathrm{~b}$.

BAROM, Wilian C. C. Didática da História e consciência histórica: pesquisa na Pósgraduação brasileira (2001-2009). Dissertação (Mestrado em Educação) - Universidade Estadual de Ponta Grossa (UEPG). Ponta Grossa, 2012.

. Os micro campos da Didática da História: a teoria da história de Jörn Rüsen, pesquisas acadêmicas e o ensino da história. Revista de Teoria da História, v.11, p.15-67, 2014.

.; CERRI, L. F. O ensino da história a partir da teoria de Jörn Rüsen. In: SEMINÁRIO DE PESQUISAS DO PPE, 2011, Maringá. Anais..., 2011.

BONETE, Wilian Jr. Notas sobre o conceito de consciência histórica e narrativa em Jörn Rüsen e Agnes Heller. Revista Eletrônica História em Reflexão, v.7, n.14, jan. 2013. Disponível em: http://www.periodicos.ufgd.edu.br/index.php/historiaemreflexao/article/view/2944/1634

CALDAS, Pedro S. P. A arquitetura da teoria: o complemento da trilogia de Jörn Rüsen. Fênix - Revista de História e Estudos Culturais, v.5, n.1, 2008.

CARDOSO, Oldimar. Para uma definição de Didática da História. Revista Brasileira de História, v.28, p.153-170, 2008.

CARVALHO, Raphael G. Jörn Rüsen e os fundamentos teóricos da didática da história (resenha). Revista de Teoria da História, v.11, p.358-368, 2014.

. Sobre a interpretação em história: uma leitura cruzada de Jörn Rüsen e Paul Ricoeur. In: AZEVEDO, Denilton N.; MARTINS, Gelise P. (Org.) (Auto)biografias e trajetórias: incursões na história cultural, política e intelectual. Curitiba: CRV, 2014b. v.1, p.165-203.

. Sobre o sentido do passado: debates acerca do conceito de narrativa na Teoria da História. Revista Expedições - Teoria da história e historiografia, v.2, p.4571, 2011.

CERRI, Luis F. Ensino de História: fronteiras interdisciplinares, avanços e problemas. Cadernos de História, Uberlândia: UFU, v.12, n.1, p.7-21, 2005.

. Didática da História no século XX: uma reflexão didática na história do Ensino de História no Brasil. Disponível em: http://www.pr.anpuh.org/resources/ anpuhpr/anais/ixencontro/comunicacao-coordenada/Didaticas\%20da\%20historia\%20do\%20seculo\%20xx/LuisFCerri.htm; Acesso em: 4 out. 2015. 
CERRI, Luis F. Didática da História: uma leitura teórica sobre a História na prática. Revista de História Regional, v.15, p.264-278, 2010.

. Os conceitos de consciência histórica e os desafios da Didática da História. Revista de História Regional, Ponta Grossa, PR, v.6, n.2, p.93-112, 2001.

CHAVES DA SILVA, Rogério. A Dimensão Narrativa e a Didática da História em Jörn Rüsen. (Resenha de RÜSEN, Jörn. História Viva: Teoria da História III - formas e funções do conhecimento histórico). Opsis, Goiânia: UFG, v.9, p.173, 2009.

DROYSEN, Johan G. Manual de Teoria da História. Petrópolis: Vozes, 2009.

FREITAS, Itamar; OLIVEIRA, Margarida M. D. de. Cultura histórica e livro didático ideal: algumas contribuições de categorias rüsenianas para um ensino de História à brasileira. Espaço Pedagógico, v.21, p.223-234, 2014.

GOMES, Wilson de S. Aproximações de fronteiras: discussão sobre Teoria da História e Historiografia nas perspectivas de Rüsen e Droysen. Revista Expedições - Teoria da História \& Historiografia, v.V, n.3, p.170-183, 2012.

MARTINS, Estevão C. R. Cultura, história, cultura histórica. ArtCultura, Uberlândia: UFU, v.25, p.61-79, 2013.

. História: consciência, pensamento, cultura, ensino. Educar em Revista, v.42, p.43-58, 2012.

. Historicismo: o útil e o desagradável. In: VARELLA, Flávia F. et al. (Org.) A dinâmica do historicismo: revisitando a historiografia moderna. Belo Horizonte: Argvmentvm, 2008.

. Memória e experiência vivida: a domesticação do tempo na história. Antíteses, Londrina, PR, v.1, p.17-30, 2008.

NADAI, Elza. O ensino da História no Brasil: trajetória e perspectiva. Revista Brasileira de História, São Paulo, v.13, n.25/26, 1993.

RÜSEN, Jörn. Razão histórica: teoria da História: os fundamentos da ciência histórica. Trad. Estevão de R. Martins e Asta-Rose Alcaide. Brasília: Ed.UnB, 2001.

. Reconstrução do Passado: teoria da História II: os princípios da pesquisa histórica. Trad. Estevão de R. Martins e Asta-Rose Alcaide. Brasília: Ed. UnB, 2007b.

. História Viva: teoria da História III: formas e funções do conhecimento histórico. Trad. Estevão de R. Martins e Asta-Rose Alcaide. Brasília: Ed. UnB, 2007a.

SADDI, Rafael. Didática da História como subdisciplina da ciência histórica. História \& Ensino, v.16, p.61-80, 2010.

. Didática da História na Alemanha e no Brasil: considerações sobre o am- 
biente do surgimento da Neu Geschichtsdidaktik na Alemanha e os desafios da Nova Didática da História no Brasil. Opsis, Goiânia: UFG, v.14, p.133-147, 2014.

SADDI, Rafael. O parafuso da didática da história: o objeto de pesquisa e o campo de investigação de uma didática da história ampliada. Acta Scientiarum. Education, v.34, p.211-220, 2012.

SCHMIDT, Maria A. M. S. Cultura histórica e aprendizagem histórica. Revista NUPEM (on-line), v.6, p.31-50, 2014a. Disponível em: http://www.fecilcam.br/revista/index.php/nupem/article/view/526.

Formação da consciência histórica ou desenvolvimento de competências? Considerações sobre o ensino de história para jovens brasileiros. Diálogos, Maringá, v.19, p.87, 2015.

. Significância e aprendizagem: contribuições para a Didática da História. Revista Eletrônica Documento/Monumento, v.12, p.22-32, 2014. Disponível em: http://200.129.241.80/ndihr/revista/revistas-anteriores/revista-dm-12.pdf.

SILVA, Luiz Sergio D. da. Ação Comunicativa e Teoria da História: aproximação de Habermas e Rüsen. História. Debates e Tendências, Passo Fundo, RS, v.2, n.1, p.23-32, 2001.

. Leituras do historicismo antes e depois do holocausto: Benjamin e Rüsen. Revista de Teoria da História, v.1, p.32-42, 2009.

. Rüsen e a Teoria da História Hoje. In: ENCONTRO REGIONAL DA ASSOCIAÇÃO NACIONAL DOS PROFESSORES DE HISTÓRIA-GO, VII., 2000, Goiânia. Minorias: identidade e memórias. Anais... Goiânia: Anpuh, 2000. v.1, p.18-18.

. Rüsen e a função do pensamento histórico. In: SEMINÁRIO PERSPECTIVAS DO ENSINO DE HISTÓRIA, IV., 2001, Ouro Preto. Caderno de Resumos... Ouro Preto: Ufop; UNP, 2001. v.1, p.80-81.

WHITE, Hayden. Enredo e verdade na escrita da história. In: MALERBA, Jurandir. A história escrita: teoria e História da historiografia. São Paulo: Contexto, 2009.

\section{NOTAS}

${ }^{1}$ Levantamento realizado para o trabalho dissertativo intitulado Didática da História e Consciência Histórica: pesquisas na pós-graduação brasileira (2001-2009), publicado em 2012 pelo programa de Educação da Universidade Estadual de Ponta Grossa, PR. Esse trabalho utilizou-se da metodologia de pesquisa documental, e o levantamento foi possível com a utilização da ferramenta Plataforma Lattes e sítio Google Acadêmico.

${ }^{2}$ Definição própria do site Google para o Google Acadêmico: "O Google Acadêmico fornece uma maneira simples de pesquisar literatura acadêmica de forma abrangente. Você po- 
de pesquisar várias disciplinas e fontes em um só lugar: artigos revisados por especialistas (peer-reviewed), teses, livros, resumos e artigos de editoras acadêmicas, organizações profissionais, bibliotecas de pré-publicações, universidades e outras entidades acadêmicas. O Google Acadêmico ajuda a identificar as pesquisas mais relevantes do mundo acadêmico". Disponível em: http://scholar.google.com.br/intl/pt-BR/scholar/about.htm; Acesso em: 11 jun. 2011. Em suas buscas, o Google Acadêmico também varre o banco de teses e dissertações da Capes. Ver: http://colecao.capes.gov.br/espanhol/paginaInicial/googleAcademico. htm e http://scholar.google.com.br/intl/pt-BR/scholar/help.html.

${ }^{3}$ Atualmente, estamos reanalisando esses trabalhos, junto aos artigos, de modo a construir uma ideia mais detalhada acerca do impacto da teoria rüseniana no pensamento educacional brasileiro, em especial, no que se refere ao ensino da história.

${ }^{4}$ Obviamente, não descartamos o fato de o formato artigo ser sintético, o que vai ao encontro das necessidades do pesquisador brasileiro, que vive num tempo atribulado.

${ }^{5}$ ASSIS, 2004.

${ }^{6}$ Reconhecemos a polissemia em torno do conceito historicismo, o que dificulta qualquer tentativa de definição consensual. De modo breve, indico aqui duas possibilidades de definição: historicismo alemão como o movimento intelectual encampado pela Escola Histórica Alemã no século XIX, que abriu novas perspectivas para a definição do método histórico e para a autonomia da História ao lado das demais ciências humanas (Ver apresentação de Julio Bentivoglio em DROYSEN, 2009, p.7); e um modo de pensar que considera a História como um conhecimento específico dos tempos passados, distinto do conhecimento do tempo presente, mas que coloca aqueles em perspectiva com este e com o tempo futuro, regulado metodicamente (vale dizer cientificamente) mediante a operação mental da compreensão (MARTINS, 2008, p.17-18).

${ }^{7}$ CHAVES DA SILVA, 2009.

${ }^{8}$ Em sua obra A teoria da História de Jörn Rüsen (2010), Arthur Assis aponta como contexto para a Teoria da História de Rüsen as inúmeras construções teóricas importadas das ciências sociais que pluralizaram e multiperspectivaram as teorias, métodos, objetos, documentos e concepções de tempo no interior da ciência da história, ao longo do século XX. Este foi o desafio a que Rüsen se submeteu, elaborar uma grande Teoria da História capaz de lidar com os diferentes paradigmas existentes da ciência da História, como o historicismo, o positivismo, o marxismo, a hermenêutica e a história social. Daí sua preocupação com os princípios formais que são comuns aos estudos históricos em todas as suas variantes. Ou seja, o trabalho de Rüsen cumpre uma função comunicativa, e a razão possível na história deriva dessa base de possibilidade de comunicação entre escolas historiográficas e vertentes metodológicas do trabalho com os documentos.

9 "A diferença de Rüsen para com a linguistic turn e a crítica pós-moderna é que aí os procedimentos linguísticos da representação histórica são tomados como o determinante básico do pensamento histórico em detrimento das operações metódicas da pesquisa, 'a qualidade estética da história ... contraposta à racionalidade metódica de seu conhecimento' 
(RÜSEN, 2001, p.150). Em última análise, sua matriz disciplinar defende que a ciência histórica tem por função cultural a 'constituição de sentido' - orientação das intenções, motivações e planos do agir racional - sem dissociar o acontecimento de suas interpretações” (CARVALHO, 2011, p.20).

${ }^{10}$ CERRI, 2001.

${ }^{11}$ De acordo com Cerri (2001, p.99), a apropriação do conceito de consciência histórica de Rüsen aproxima-se da mesma apropriação de Agnes Heller, diferenciando-se da de Hans-Georg Gadamer e Philippe Ariès. Na análise de nossa amostragem de artigos, pudemos perceber uma intenção em aproximar Rüsen a inúmeros outros teóricos. Por postular uma teoria eclética, Rüsen vem apresentando várias frentes de aproximações. Ver aproximações a Habermas (DUARTE DA SILVA, 2000; CERRI, 2010), a Freire (CERRI, 2010; SCHMIDT, 2015), a Droysen (GOMES, 2012), a Agnes Heller (CERRI, 2001; BENETE, 2013), a Paul Ricoeur (CARVALHO, 2014b), a Koselleck (ALVES, 2014a), e a Benjamin (SILVA, 2009).

${ }^{12}$ Sobre a crítica de Rüsen à formação compensatória: "A formação é compensatória quando, acriticamente, de fora da produção científica do saber ou contra ela, deixa-a ao sabor de suas próprias regras, separa da racionalidade intrínseca ao saber científico as carências de orientação voltadas ao todo, à relação à vida e à subjetividade, enfim, satisfaz essas carências com meios não científicos. Nesse caso, é a arte a mais utilizada, comprometendo irreversivelmente a dimensão cognitiva da compreensão humana do mundo e a autointerpretação dos homens" (RÜSEN, 2007a, p.96).

${ }^{13}$ Todos esses conceitos estão desenvolvidos na trilogia rüseniana intitulada Fundamentos de uma teoria da História, publicada na Alemanha ao longo da década de 1980, e que no Brasil foi lançada na última década, na tradução dos professores Dr. Estevão Chaves de Rezende Martins e Asta-Rose Alcaide, da Universidade de Brasília (UnB). A Editora da UnB lançou esses três textos no Brasil em dois momentos distintos: em 2001, o primeiro volume foi lançado sob o título de Razão Histórica: os fundamentos da ciência histórica, ganhando sequência apenas no ano de 2007, com os títulos Reconstrução do Passado: os princípios da pesquisa histórica e História Viva: formas e funções do conhecimento histórico. Estas obras se complementam e estruturam a teoria de Rüsen, abrangendo desde a presença do pensamento histórico na vida prática, sua metodização e regras na esfera científica, e, por fim, o questionamento das formas como este conhecimento científico se apresenta e retorna como orientação na vida prática.

${ }^{14}$ Sobre a inserção da subjetividade, observemos como Oldimar Cardoso Pontes descreve a pesquisa didático-histórica: "um discurso de um profissional da cultura histórica sobre essa mesma cultura, que tem um grande impacto, pois limita o seu diálogo com outras disciplinas em função da coerência entre elas e a cultura histórica ... A pesquisa de campo didático-histórica não se dirige até a escola para entrevistar professores e alunos, mas para conviver e experienciar com eles ... O estranhamento não é uma condição de êxito de pesquisas de campo didático-históricas porque as diferentes experiências e vivências profissionais do pesquisador na área da cultura histórica não são obstáculos à análise do contex- 
to de campo. Pelo contrário, essas experiências e vivências são um elemento indispensável à realização da pesquisa enquanto auto-reflexão. A familiaridade do pesquisador com a cultura histórica não é um problema, mas a condição sine qua non da pesquisa didático-histórica. É somente o confronto das experiências e vivências do pesquisador com as do contexto de campo que possibilita a auto-reflexão sobre a cultura histórica" (Cardoso, 2008, p.162).

${ }^{15} \mathrm{Um}$ artigo que complementa esse encontro é ALVES, 2013.

${ }^{16}$ SCHMIDT, 2014, p.46.

${ }^{17}$ Pergunta realizada no evento VIII Seminário da Educação Histórica, que correu em Curitiba, 2015. Site do evento: https://lapeduh.wordpress.com/arquivos/seminarios-de-educacao-historica/viii-seminario-de-educacao-historica-2015/.

${ }^{18}$ A expressão "crise", em seu texto, não denota uma visão negativa ou de decadência, mas sim de transição entre um momento de modelo único e padrão, definido como "história historicista" (NADAI, 1993, p.144), hegemônico em suas implicações ao ensino da história, para um momento no qual a unidade da ciência da história já não existe mais, "crise da história historicista", o que também possibilita como consequência a multiperspectividade teórica e metodológica ao ensino da História. Elza Nadai não justificou, ou conceituou, sua utilização do termo historicismo em seu texto.

${ }^{19}$ Tema da Conferência de Jörn Rüsen no lançamento dos seus livros Teoria da História uma teoria da História como ciência e Humanismo e Didática da História, no VIII Seminário da Educação Histórica (Curitiba, 21 set. 2015), tema também discutido ao longo do evento por diversos apresentadores.

Artigo recebido em 6 de outubro de 2015. Aprovado em 4 de novembro de 2015. 